\title{
Schistosoma haematobium, Plasmodium falciparum infection and anaemia in children in Accra, Ghana
}

\author{
Ruth Nyarko, Kwasi Torpey ${ }^{*}$ and Augustine Ankomah
}

\begin{abstract}
Background: Urinary Schistosomiasis and malaria are endemic in Sub-Saharan Africa. There are public health concerns and implications of these parasites. This study sought to assess the prevalence of malaria, urinary schistosomiasis, and anaemia in children of school going age in two municipalities in Ghana.

Methods: A cross-sectional study design was used to investigate the prevalence of S. haematobium, P. falciparum infection and the haemoglobin concentration of respondents. A total of 404 (231 males and 173 females) school children between ages 9 - 14 years (mean age 11.8 \pm 1.4 years) were recruited for the survey. Urine and blood samples were collected using standard operating procedures for urinary schistosomiasis and malaria diagnosis. Haemoglobin concentration was measured using a Hemocue ${ }^{\circledast} \mathrm{Hb} 201 \mathrm{~m}$.

Results: The prevalence of mono-infection was 4.7 and $12.9 \%$ for $S$. haematobium and $P$. falciparum respectively with a small proportion (0.9\%) of the respondents infected with both parasites. The prevalence of anaemia in the study population was 59.9\%. The risk of developing anaemia was not associated with being infected with any of the parasites. All co-infected children had anaemia.

Conclusion: High prevalence of anaemia was observed within the study population. Prevalence of malaria was higher compared to schistosomiasis. Interventions to address the high levels of anaemia is required within the community.
\end{abstract}

Keywords: Schistosoma haematobium, Plasmodium falciparum, Hemoglobin, Anaemia, School children

\section{Background}

Malaria and urinary schistosomiasis are parasitic infections with grave public health implications. Both parasites have been associated with poverty and several related factors which may result in their distribution [1]. Some predisposing factors include low socio economic status, poor sanitation, and limited access to safe water, development of water resource and poor education and awareness play a key role in the transmission and infestation of malaria and schistosome parasites. Children are most vulnerable to schistosome and malaria infection due to their exposure to the infectious agents in activities of daily living.

Urinary schistosomiasis caused by $S$. haematobium is the most common form of schistosomiasis in Ghana.

\footnotetext{
* Correspondence: ktorpey@hotmail.com

School of Public Health, University of Ghana, P. O Box LG 13, Legon, Accra, Ghana
}

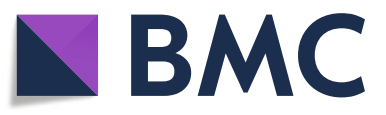

(c) The Author(s). 2018 Open Access This article is distributed under the terms of the Creative Commons Attribution 4.0 International License (http://creativecommons.org/licenses/by/4.0/), which permits unrestricted use, distribution, and reproduction in any medium, provided you give appropriate credit to the original author(s) and the source, provide a link to the Creative Commons license, and indicate if changes were made. The Creative Commons Public Domain Dedication waiver (http://creativecommons.org/publicdomain/zero/1.0/) applies to the data made available in this article, unless otherwise stated. cause they live in blood vessels. Its transmission requires an intermediate and suitable snail host. Contamination of water bodies with human excreta and urine releases the primary larvae (miracidiae) which infects the snails and develops into free-living secondary larvae in the snail host. Water-related activities such as swimming, fishing, irrigation or farming, fetching of water and washing clothes or dishes expose humans to the cercariae. The cercariae penetrate the skin thereby infecting humans in the process $[2,3]$. The creation of dams and urbanization facilitates the development of the habitat for snails and consequently increases the local prevalence of schistosomiasis [2, 3]. S. haematobium deposits eggs in the host bladder which induces inflammation and causes ulceration resulting in haematuria [3, 4]. 
Reported prevalence in Ghana ranged from 1.5 to $52 \%$ [5-7].

Malaria in Ghana is commonly caused by the Plasmodium falciparum infection which is transmitted through the bite of the female anopheles mosquito [8]. The total parasitaemia prevalence reported among school children in Ashanti Region and Wa West District in Ghana was $42 \%$ [9]. The risk of developing low haemoglobin concentration has been associated with $P$. falciparum infection [10]. Malaria parasites break down red blood cells and increase splenic clearance of both infected and noninfected red blood cells [10]. The reported prevalence of coinfection with $P$. falciparum and $S$. haematobium in Africa ranges from 2.84 to $57.1 \%$ [10-12].

This study sought to assess the prevalence of malaria, schistosomiasis, and anaemia among children of schoolgoing age in six peri-urban areas located in Ga South and Ga West municipality in Ghana.

\section{Methods}

\section{Study area}

This study was carried out in two different municipalities in Ghana; Ga West and Ga South Municipality. This geographic area was selected due to the presence of water bodies which serves as a source of drinking water for more than 4million people living in the Greater Accra Region. Three schools were selected in each municipality using purposive sampling.

\section{Study design}

An analytical cross-sectional study design was used to investigate the relationship between $S$. haematobium, $P$. falciparum and the haemoglobin concentration of school children. Three schools were selected based on proximity to open source of water in the two districts. Proportionate stratified sampling technique was used to determine the number of participants to be recruited in each grade in all the participating schools. Simple random sampling was used in selecting participants from each grade in the six schools. Children were recruited from grade 3 to grade 6 which constituted an age range of 9 to 14 years.

Sample size determination: a prevalence of $50 \%$ (for $S$. haematobium and P. falciparum infection) was used to compute the sample size at a $95 \%$ confidence level and a statistical power of $90 \%$. The minimum sample size calculated for this study was 253 participants.

\section{Data collection and analysis}

The study was conducted between April and June 2016. A structured questionnaire was used to collect data from the respondents. Sociodemographic data such as such as name, age, sex, the residence and length of stay in the community. The socio-economic status was measured using a tool developed by the Center for Social Research which has also been used in similar studies (Additional file 1) [13]. The tool combined six variables; type of roofing material, household water source, the occupation of household head, type or availability of toilet facility, floor material and household assets $\mathrm{A}$ weight ranging from 0 to 2 was assigned to each asset under the six variables. Weights were assigned based on the value of the assets. The sum of the weights obtained from the six variables was used to derive a score which determined the socioeconomic status for each household. Households were classified as low SES for those with scores less than 4.0, moderate SES for 4.0-6.0 and high SES for a score more than 6.0. However, the tool was modified to be relevant to the context within which the study was carried out.

\section{Plasmodium falciparum infection}

Presence of $P$. falciparum was detected using a Rapid Diagnostic Test Kit (CareStart ${ }^{\mathrm{Tw}}$, Access Bio, Inc.). The CareStart Kit was used because P. falciparum infection is the commonest occurring infection which accounts for more than $90 \%$ of all cases of malaria [14]. Each respondent was provided with a clean, dry, screw-capped urine container bearing the same serial number as the questionnaire and instructions were given on the amount of urine to be provided. Urine filtration method was done using Whatman ${ }^{\circ}$ Nucleopore $^{\text {Tw }}$ Track-Etched Membranes diameter $25 \mathrm{~mm}$, pore size $12 \mu \mathrm{m}$, polycarbonate. The intensity of $S$. haematobium infection (egg count per $10 \mathrm{ml}$ of urine) was determined via microscopy. Light infection was classified as $1-49$ eggs $/ 10 \mathrm{ml}$ of urine and heavy infection was defined by an egg count equal to or less than 50 eggs $/ 10 \mathrm{ml}$ of urine. Haematuria was measured using URIT $10 \mathrm{~V}$ urine reagent strips. Haemoglobin $(\mathrm{Hb})$ concentration of respondents was measured using HemoCue $\mathrm{Hb} 201^{+}$and HemoCue $\mathrm{Hb} 201^{+}$Microcuvettes.

Data were entered into Microsoft Excel 2013 and exported into STATA 13. Descriptive statistics were used to analyze the background characteristics of participants and the factors associated with S. haematobium and $P$. falciparum infection and coinfection of S. haematobium and P.falciparum. Differences in the prevalence of mono-infection and coinfection were determined using a chi-square analysis. Multivariate logistic regression analysis was used to predict association with the different infection status as the dependent variable and other independent variables. Differences in the mean hemoglobin level of the different infection status and socio-demographic variables were analyzed using a one-way ANOVA. Values were considered to be significant when $p$-values were less than 0.05 . 


\section{Inclusion and exclusion criteria}

Children who were not in grade 3 to grade 6 were excluded from the study. Children who did not provide both assent and parental consent were excluded from the study.

\section{Results}

\section{Background characteristics}

The study had a response rate of $97 \%$ with 404 out of 414 expected participants responded to the study. More than half $(57.2 \%)$ of the respondents were males with the majority (63.0\%) being between 12 and 14 years old. The children had a mean age of $11.8 \pm 1.4$ years. Most of the children were from families with moderate socioeconomic status (Table 1 ).

\section{S. haematobium, $P$. falciparum and coinfection prevalence pattern}

Prevalence of urinary schistosomiasis in the schools ranged from 0 to $10.3 \%$. Out of the 404 respondents, $4.7 \%$ $(N=19)$ of the respondents had a positive diagnosis for schistosomiasis based on the egg count by microscopy whilst $5.2 \%$ of the participants had haematuria (Table 2). The observed difference in the prevalence of urinary schistosomiasis between the two districts was not statistically significant. Infection with $S$. haematobium was not gender or socioeconomic status dependent. However, there was an increasing trend with increasing age, with the highest prevalence of $6.3 \%$ recorded for the age group 12 to 14 years $[(\mathrm{OR}=3.87, \mathrm{CI}=1.03-14.41), P$-value $=0$. 044] (Table 2). Respondents infected with $S$. haematobium were categorized into the light and heavy infection. Light infection in the study was defined as an egg count of less than $50 \mathrm{eggs} / 10 \mathrm{ml}$ of urine and heavy infection was defined as an egg count of 50 or more eggs per $10 \mathrm{ml}$ of urine. The egg count of respondents ranged from 1 to 204 eggs/10 $\mathrm{ml}$ of urine with an average egg count of $2.3 \pm 0.9$ eggs/10 $\mathrm{ml}$ of urine.

Table 1 Background characteristics of respondents

\begin{tabular}{lll}
\hline Background characteristics & Frequency $(\mathrm{n})$ & Percent (\%) \\
\hline Sex & 231 & 57.2 \\
Male & 173 & 42.8 \\
Female & & \\
Age & 151 & 37.4 \\
$9-11$ & 253 & 62.6 \\
12-14 & & \\
Grade & & \\
Socio-economic status & 30 & 7.4 \\
$\quad$ Low & 227 & 56.2 \\
$\quad$ Moderate & 147 & 36.4 \\
High &
\end{tabular}

The prevalence of malaria among the study population was $12.9 \%$. Prevalence was higher in Ga West (18.8\%) municipality than in Ga South $(6.6 \%)[(\mathrm{OR}=3.87, \mathrm{CI}=0$. 16-0.59), $P$-value <0.001]. Prevalence of malaria was neither associated with gender, age or socioeconomic status (Table 2).

Out of the 404 respondents, only 4 (0.9\%) school children had concomitant P. falciparum and S. haematobium infection (Table 2).

The mean haemoglobin level among respondents was $11.6 \mathrm{~g} / \mathrm{dl} \pm 1.5$ with a range of $5.5 \mathrm{~g} / \mathrm{dl}$ to $15.1 \mathrm{~g} / \mathrm{dl}$. Children within the age group 12-14 years had a higher mean haemoglobin concentration compared to the 911 years age group. Grade 6 children had the highest haemoglobin concentration whereas grade 4 respondents had the lowest haemoglobin level. Table 3 shows a significant difference $(p<0.05)$ in the haemoglobin level between $S$. haematobium positive and negative individuals. There was a significant difference in the mean haemoglobin concentration of respondents with light and heavy infection for S. haematobium. Children with heavy infection had a lower mean haemoglobin level than children with light infection. P. falciparum infected children had lower haemoglobin concentration compared with children not infected with P. falciparum (Table 3).

\section{Discussion}

The overall prevalence of $4.7 \%$ reported for urinary schistosomiasis in this study was less than the prevalence reported in similar studies in Nigeria and Ethiopia $[10,11,15]$. Previous studies in Galilea, peri-urban community in Ga South municipality and in the Northern region of Ghana respectively reported a prevalence of 52 and 33\% for urinary schistosomiasis higher than the prevalence found in this study $[6,7]$. The reduced prevalence in this study can be attributed to improvement in sanitation, the supply of safe water, awareness about the disease and the year to year administration of praziquantel to the school children in all the selected schools [15]. The high prevalence of light infection is consistent with similar studies in Nigeria and Malawi $[13,16]$. The total prevalence for P. falciparum (12.9\%), reported in this study was lower than the prevalence in a similar population [9]. The observed difference for $P$. falciparum infection could be attributed to the use of malaria prevention methods such as insecticide-treated nets and insecticides. Previous studies in same study site revealed a prevalence between 54 and $60 \%$ for urinary schistosomiasis [17]. The year to year praziquantel chemotherapy could have influenced the reduction in the prevalence of urinary schistosomiasis. Praziquantel has proven effective in reducing the prevalence and intensity of infection and risk of reinfection with S. haematobium [18]. 
Table 2 A multivariate analysis showing the prevalence pattern of S. haematobium, P. falciparum and coinfection

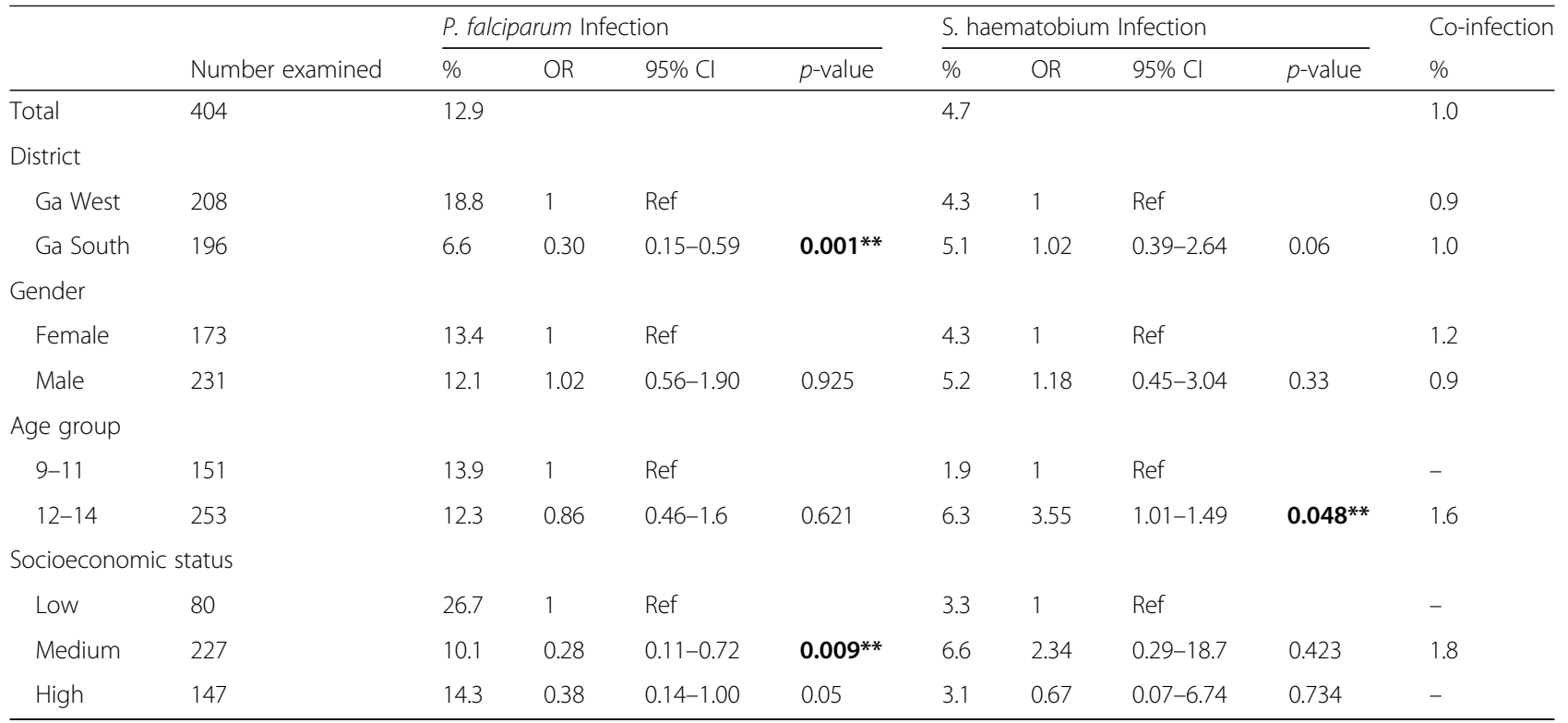

**Significant at the 0.05 probability level

The total prevalence of anaemia in the study was 59 . $9 \%$ which is indicative of a severe public health problem [19]. In Ethiopia, an anaemia prevalence of $81 \%$ was reported among children of school going age [15]. Inadequate nutritional intake, low socioeconomic status, and worm infestation are possible risk factors for the observed high prevalence of anaemia in the study.

The mean haemoglobin concentration of the study population was $11.6 \pm 1.5 \mathrm{~g} / \mathrm{dl}$. This is because the prevalence of mild anaemia was higher than the prevalence of moderate and severe anaemia. This finding is similar to other studies among children of school going age $[9,20]$.

Although haemoglobin concentration of $P$. falciparum infected children was lower than S. haematobium infected respondents, malaria was not a discriminatory factor to anaemia. This could be attributed to the high endemicity of $P$. falciparum among the study respondents resulting in misclassification. Children who were lightly infected with $S$. haematobium had a higher haemoglobin concentration because they are less likely to have haematuria. The Plasmodium parasites break down red blood cells and increase the clearance of both infected and uninfected red blood cells and a reduction in erythropoiesis [21]. Similar findings of a higher risk of lower hemoglobin concentration with P. falciparum infection was reported in Nigeria [10]. Respondents with light infection had a significantly higher haemoglobin concentration compared with respondents with heavy infection $(p$-value $<0.05)$ thus contributing to the higher haemoglobin concentration in S. haematobium infected respondents. The intensity of $S$. haematobium infection is positively correlated with hemoglobin concentration [15].
All respondents with coinfection had anaemia. In Ethiopia children with concurrent S. haematobium and $P$. falciparum infection had a lower hemoglobin concentration than children with mono-infection [15]. The concurrent infection with both parasites may have enhanced their risk of anaemia in the children who were co-infected.

The reported prevalence of hookworm infection in Ghana ranges from 3.2 to $10 \%[22,23]$. There is currently on-going helminth control program in the two districts. School children are given albendazole treatment for worm infection and praziquantel administration for schistosomiasis. Helminthic infestation particularly hookworms can lead to anaemia. Though the study did not assess the nutritional status and prevalence of helminthic infections, anaemia due to the worm infestation is unlikely given the ongoing interventions in the area.

Further studies, taking into consideration, these confounders should be carried to obtain the true relationship between these risk factors and haemoglobin concentration in school children. This is necessary to understand the causes of the high levels of anaemia for the formulation of appropriate public health intervention.

\section{Conclusions}

High prevalence of anaemia within the study communities is of concern. Investigating common causes of low hemoglobin concentration such as helminth infection and nutritional intake among others is required to address the challenge. Furthermore, public health interventions to reduce the prevalence of malaria and schistosomiasis particularly among school going children is warranted. 
Table 3 A Multivariate Analysis of Haemoglobin concentration

\begin{tabular}{|c|c|c|c|c|}
\hline & \multicolumn{4}{|c|}{ Hemoglobin concentration } \\
\hline & $\mathrm{Hb}(\mathrm{g} / \mathrm{dl}) \pm \mathrm{SD}$ & Minimum Hb(g/dl) & Maximum $\mathrm{Hb}(\mathrm{g} / \mathrm{dl})$ & $P$ - value \\
\hline Total & $11.6 \pm 1.5$ & 5.5 & 15.1 & \\
\hline \multicolumn{5}{|l|}{ District } \\
\hline Ga West & $11.5 \pm 1.4$ & 5.5 & 14.5 & \multirow[t]{2}{*}{0.146} \\
\hline Ga South & $11.7 \pm 1.5$ & 7 & 15.1 & \\
\hline \multicolumn{5}{|l|}{ Age } \\
\hline $9-11$ & $11.3 \pm 1.5$ & 5.5 & 14.2 & \multirow[t]{2}{*}{$0.001 * *$} \\
\hline $12-14$ & $11.8 \pm 1.4$ & 7 & 15.1 & \\
\hline \multicolumn{5}{|l|}{ Sex } \\
\hline Male & $11.6 \pm 1.3$ & 7.7 & 15.1 & \multirow[t]{2}{*}{0.431} \\
\hline Female & $11.5 \pm 1.6$ & 5.5 & 15.1 & \\
\hline \multicolumn{5}{|l|}{ Socioeconomic status } \\
\hline Low & $11.4 \pm 1.7$ & 5.5 & 14.1 & \multirow[t]{3}{*}{0.103} \\
\hline Moderate & $11.7 \pm 1.4$ & 6.2 & 15.1 & \\
\hline High & $11.4 \pm 1.5$ & 7 & 14.7 & \\
\hline \multicolumn{5}{|l|}{ Hematuria } \\
\hline Present & $12.3 \pm 1.4$ & 10.2 & 15.1 & \multirow[t]{2}{*}{$0.016^{* *}$} \\
\hline Absent & $11.6 \pm 1.4$ & 5.5 & 15.1 & \\
\hline \multicolumn{5}{|l|}{ Infection status } \\
\hline Schistosomiasis Positive & $12.3 \pm 1.7$ & 8.5 & 15.1 & \multirow[t]{2}{*}{$0.0332^{* *}$} \\
\hline Schistosomiasis Negative & $11.6 \pm 1.4$ & 5.5 & 15.1 & \\
\hline Malaria Positive & $11.4 \pm 1.2$ & 8.6 & 13.5 & \multirow[t]{2}{*}{0.3139} \\
\hline Malaria Negative & $11.6 \pm 1.5$ & 5.5 & 15.1 & \\
\hline \multicolumn{5}{|c|}{ Intensity of S. haematobium infection } \\
\hline light infection & $12.9 \pm 1.5$ & 10.7 & 15.1 & \multirow[t]{2}{*}{$0.003^{* *}$} \\
\hline heavy infection & $11.2 \pm 1.5$ & 8.5 & 13.3 & \\
\hline
\end{tabular}

**Significant at the 0.05 probability level

\section{Additional file}

Additional file 1: Socioeconomic Status Tool. (DOCX 48 kb)

\section{Abbreviations}

Hb: Hemoglobin; ITN: Insecticide treated net; WHO/ TDR: World Health Organisation/ Tropical Disease Research

\section{Acknowledgments}

We acknowledge the Directors of Education in the Ga South and Ga West Municipality, The various School heads, parents and the children who assisted in making this study a success. We also acknowledge, Prof Mante Bosompem, Mr. Joseph Otchere, Mr. Edward Dumashie and Mrs. Yvonne Quartey of the Parasitology Unit at the Noguchi Memorial Institute for Medical Research for their immense contribution during sample collection and laboratory analysis.

\section{Funding}

This study was supported by WHO/TDR during collection of data and analysis of laboratory samples. The funding body had no role in the design of the study, the collection, analysis, and interpretation of data, or in writing the manuscript.

\section{Availability of data and materials}

The datasets generated and analyzed in this study are not publicly available but are available from the corresponding author on reasonable request.

\section{Authors' contributions}

$K T$ made a substantial contribution to the conception and design of the study and was involved in the drafting of the manuscript and final approval of the version to be published. AA made a substantial contribution to the conception and design of the study. RT was involved in the drafting of the proposal, data collection and laboratory analysis, analysis of data and drafting of the manuscript. All authors read and approved the final manuscript.

\section{Ethics approval and consent to participate}

Ethical approval was given by the Ghana Health Service Ethics Review Committee (GHS-ERC-73/02/16). Consent was sought from the Ghana Education Service in the various districts, head teachers and parents. Assent was sought from the students before data collection.

\section{Competing interests}

The authors declare that they have no competing interests.

\section{Publisher's Note}

Springer Nature remains neutral with regard to jurisdictional claims in published maps and institutional affiliations. 
Received: 9 October 2017 Accepted: 11 April 2018

Published online: 18 April 2018

\section{References}

1. Degarege A, Mekonnen Z, Levecke B, Legesse M, Negash Y, Vercruysse J, Levecke B. Prevalence of Schistosoma haematobium infection among school-age children in afar area, northeastern Ethiopia. PLoS One. 2015; https://doi.org/10.1371/journal.pone.0133142.

2. Bustinduy $\mathrm{AL}$, King $\mathrm{CH}$. Helminthic infections: schistosomiasis. In: Masons Tropical Diseases; 2011. https://doi.org/10.1016/B978-0-7020-5101-2.00053-4.

3. Gryseels B, Strickland GT. Schistosomiasis. In: Hunter's tropical medicine and emerging infectious disease; 2013. https://doi.org/10.1016/B978-1-41604390-4.00122-3.

4. Bustinduy A, King C, Scott J, Appleton S, Sousa-Figueiredo JC, Betson M, Stothard JR. HIV and schistosomiasis co-infection in African children. Lancet Infect Dis. 2014; https://doi.org/10.1016/S1473-3099(14)70001-5.

5. Clara A. Helminth and Plasmodium falciparum infections among inhabitants of the tono irrigation catchment area in the upper East Region; 2012. https://doi.org/10.1017/CBO9781107415324.004.

6. Aboagye I, Edoh D. Investigation of the risk of infection of urinary schistosomiasis at Mahem and Galilea communities in the Greater Accra region of Ghana. West African J Appl Ecol. 2010; https://doi.org/10.4314/ wajae.v15i1.49426.

7. Anto F, Asoala V, Adjuik M, Anyorigiya T, Oduro A, Akazili J, Akweongo P, Ayivor P, Bimi L, Hodgson A. Water contact activities and prevalence of schistosomiasis infection among school-age children in communities along an irrigation scheme in rural Northern Ghana. J Bacteriol Parasitol. 2013; https://doi.org/10.4172/2155-9597.1000177.

8. Adebayo AM, Akinyemi OO, Cadmus EO. Knowledge of malaria prevention among pregnant women and female caregivers of under-five children in rural Southwest Nigeria. PeerJ. 2015; https://doi.org/10.7717/peerj.792.

9. Sarpong N, Dabo EO, Kreuels B, Fobil JN, Segbaya S, Amoyaw F, Hahn A, Kruppa T, May J. Prevalence of malaria parasitaemia in school children from two districts of Ghana earmarked for indoor residual spraying: a cross sectional study. Malar J. 2015; https://doi.org/10.1186/s12936-015-0772-6.

10. Morenikeji OA, Atanda OS, Eleng IE, Salawu OT. Schistosoma haematobium and Plasmodium falciparum single and concomitant infections; any association with hematologic abnormalities? Pediatr Infect Dis. 2014; https://doi.org/10.1016/j.pid.2014.11.001.

11. Morenikeji OA, Eleng IE, Atanda OS, Oyeyemi OT. Renal related disorders in concomitant Schistosoma haematobium-Plasmodium falciparum infection among children in a rural community of Nigeria. J Infect Public Health. 2015; https://doi.org/10.1016/j.jiph.2015.06.013.

12. Deribew $K$, Tekeste $Z$, Petros B. Urinary schistosomiasis and malaria associated anemia in Ethiopia. Asian Pac J Trop Biomed. 2013; https://doi.org/10.1016/S2221-1691(13)60068-4.

13. Kapito-Tembo AP, Mwapasa V, Meshnick SR, Samanyika Y, Banda D, Bowie $C$, et al. Prevalence distribution and risk factors for Schistosoma hematobium infection among school children in Blantyre, Malawi. PLoS Negl Trop Dis. 2009; https://doi.org/10.1371/journal.pntd.0000361.

14. Ayanful-Torgby R, Oppong A, Abankwa J, Acquah F, Wilson K, Amoah LE. Plasmodium falciparum genotype and gametocyte prevalence in children with uncomplicated malaria in coastal Ghana. BMC Malar J. 2016;15:562.

15. Deribew K, Tekeste Z, Petros B, Huat LB. Urinary schistosomiasis and malaria associated anemia in Ethiopia. Asian Pac J Trop Biomed. 2013; https://doi.org/10.1016/S2221-1691(13)60068-4.

16. Amuta EU, Houmsou RS. Prevalence, intensity of infection and risk factors of urinary schistosomiasis in pre-school and school aged children in Guma local government area, Nigeria. Asian Pac J Trop Med. 2014; https://doi.org/ 10.1016/S1995-7645(13)60188-1.

17. Aryeetey ME, Wagatsuma Y, Yeboah G, Asante M, Mensah G, Nkrumah FK, Kojima S. Urinary schistosomiasis in southern Ghana: 1. Prevalence and morbidity assessment in three (defined) rural areas drained by the Densu river. Parasitol Int. 2000; https://doi.org/10.1016/S1383-5769(00)00044-1.

18. Senghor B, Diaw OT, Doucoure S, Sylla SN, Seye M, Talla I, Bâ CT, Diallo A, Sokhna C. Efficacy of praziquantel against urinary schistosomiasis and reinfection in Senegalese school children where there is a single welldefined transmission period. Parasit Vectors. 2015; https://doi.org/10.1186/ s13071-015-0980-5.

19. World Health Organization. Haemoglobin concentrations for the diagnosis of anaemia and assessment of severity. 2011. http://apps.who.int/iris/
bitstream/10665/85839/3/WHO_NMH_NHD_MNM_11.1_eng.pdf?ua=1. Accessed 23 May 2016.

20. Gutema B, Adissu W, Asress Y, Gedefaw L. Anemia and associated factors among school-age children in Filtu town, Somali region, Southeast. BMC Hem. 2014; https://doi.org/10.1186/2052-1839-14-13.

21. Mohandas N, An X. Malaria and human red blood cells. Med Microbiol Immunol. 2012; https://doi.org/10.1007/s00430-012-0272-z.

22. Mirisho R, Neizer ML, Sarfo B. Prevalence of helminths infestation in children attending Princess Marie Louise Children's Hospital in Accra, Ghana. J Parasitol Res. 2017; https://doi.org/10.1155/2017/8524985.

23. Soares Magalhaes RJ, Biritwum NK, Gyapong JO, Brooker S, Zhang Y, Blair L, Fenwick A, Clements ACA. Mapping helminth co-infection and co-intensity: geostatistical prediction in Ghana. PLoS Negl Trop Dis. 2011; https://doi.org/ 10.1371/journal.pntd.0001200.

\section{Ready to submit your research? Choose BMC and benefit from:}

- fast, convenient online submission

- thorough peer review by experienced researchers in your field

- rapid publication on acceptance

- support for research data, including large and complex data types

- gold Open Access which fosters wider collaboration and increased citations

- maximum visibility for your research: over $100 \mathrm{M}$ website views per year

At BMC, research is always in progress.

Learn more biomedcentral.com/submissions 